Cairo, Egypt, for supplying us with the animals used in this investigation.

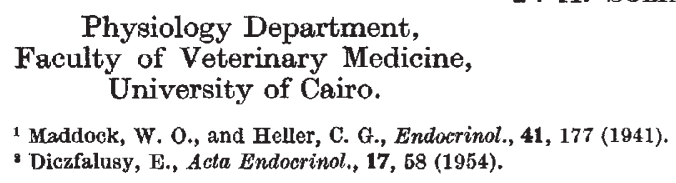

\section{Carbon Dioxide Assimilation by Leishmania donovani}

WHILE studying the glucose metabolism of Leish mania donovani, the protozoan organism causing visceral leishmaniasis, it has been found that cell suspensions of this organism in a saline-bicarbonate buffer containing glucose can assimilate a measurable amount of carbon dioxide along with the formation of different acidic end products ${ }^{1}$.

L. donovani, strain 81, cultured on Ray's medium ${ }^{2}$ at $22-24^{\circ} \mathrm{C}$. and recycled every three weeks from the Nicolle-Novy-McNeal medium, was used in this study. After growth for three days on Ray's medium, the organism was scraped from the surface of the agar, washed twice with ice-cold isotonic saline by centrifugation at 3,000 r.p.m. for $10 \mathrm{~min}$. and finally resuspended in isotonic saline.

Standard conditions used for the measurement of carbon dioxide assimilation were as follows: $3.0 \mathrm{ml}$. of the complete reaction mixture contained $15 \mu$ moles of sodium bicarbonate $(p H 7 \cdot 3), 30 \mu$ moles of glucose, $1 \mathrm{ml}$. of cell suspensions in isotonic saline containing 1.5-2 mgm. protein nitrogen. Incubations were carried out for one hour in conventional Warburg manometric vessels at $37.2^{\circ} \mathrm{C}$. in an atmosphere 95 per cent nitrogen and 5 per cent carbon dioxide.

Results from three typical experiments showing the carbon dioxide balances during anaerobic glucose breakdown by cell suspensions of $L$. donovani are presented in Table 1. It will be seen that the amount of carbon dioxide assimilated by the organisms under these conditions varies from $32 \mu l$. to $80 \mu l$. The variation in the amount of carbon dioxide fixation was afterwards found to be due to the different growth stages of the culture used. Table 2 represents figures for the stoichiometric relationship between glucose utilized, acid produced and carbon dioxide fixed in three typical experiments carried out under standard experimental conditions. It will be seen that nearly $0.30-0.36$ mole of carbon dioxide is incorporated per mole of glucose consumed. Results using growing culture indicate that the amount of carbon dioxide fixed varies with the age of culture; with two days old growing culture the molar ratio of carbon dioxide fixed per mole of glucose utilized is nearly one. From Table 2 it will also be seen that an average of 1.5 moles of acids are formed per mole of glucose metabolized. Chemical analysis of the different acids that are formed indicated that the major products were nonvolatile in nature, and among them succinic acid predominated although malic acid formation has also been noted.

Table 1. Carbon DIOXIDE BALAYCES DLRING ANABRoBic BrEakDOWN

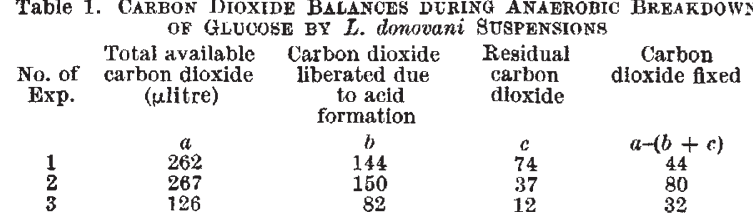

Table 2. Carbon Droxinf assmmation bY $L$, domovani Suspensions Expt. Glucose Total acid Carbon dioxide Carbon dioxide

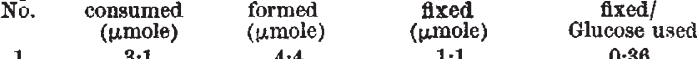

$\begin{array}{lllll}1 & 3 \cdot 1 & 4 \cdot 4 & 1 \cdot 1 & 0 \cdot 36 \\ 2 & 6 \cdot 1 & 8 \cdot 6 & 1 \cdot 9 & 0 \cdot 31 \\ 3 & 5 \cdot 3 & 7 \cdot 8 & 1 \cdot 6 & 0.30\end{array}$

When glucose was replaced by glycerol, ribose or pyruvate, no measurable amount of carbon dioxide fixation was noticed. Of the various inhibitors tried, DNP $\left(10^{-4} M\right), \alpha-\alpha^{\prime}$-dipyridyl $\left(10^{-3} M\right)$ and 8-hydroxyquinoline $\left(10^{-3} M\right)$ were found to have marked inhibitory effects on the glucose utilization as well as on the carbon dioxide assimilation. It seems that the carbon. dioxide assimilation by this protozoal organism is in some way related to the glucose metabolism. The high rate of carbon dioxide assimilation may also be complementary to the very active transaminase system reported to be present in this organism ${ }^{3}$.

Detailed studies on the biochemical basis for the carbon dioxide requirement of this protozoal organism are in progress and will be reported elsewhere.

\section{A. N, Chatterjee}

Indian Institute for Biochemistry and Experimental Medicine, Calcutta.

\section{J. J. Gновн*}

Department of Applied Chemistry, University of Calcutta. * Present address: New York State Psychiatric Institute, aud the
Department of Biochemistry, College of Physicians and Surgeons, Columbia University, New York. 1 Chatterjee, A. N., Ray, J. C., and Ghosh, J. J., Symposium on Chemo-
therapy, C.S.I.R., New Delhi, 168 (Nov., 1958).

${ }^{2}$ Ray, J. C., Ind. J. Med. Sci., 29, No. 2, 355 (1932).

${ }^{3}$ Chatterjee, A. N., and Ghosh, J. J., Nature, 180, 1425 (1967).

\section{HEMATOLOGY}

\section{Hæmolytic Properties of Immune Chicken Antibody}

Is the course of a study of immunological responsiveness of chickens to foreign red blood cells our interest was attracted by the observed discrepancy between high agglutination titres of immune chicken sera and their inability to show lytic properties in the presence of complement. It is well known that different antibody-antigen systems exhibit different abilities to fix guinea pig complement when mammals are used as antibody producers ${ }^{1}$. The failure of immune bird sera to show a significant complement-fixing activity was mentioned by Meyer ${ }^{2}$ and by Rico $^{3}$ in birds infected with ornithosis virus and S. pullorum. It was postulated that avian antibody formed with antigen non-complement-fixing aggregates 4 , and that avian antibody lacked some character that was important for combining with complement. This problem, however, was not further explored, and all available data were based on the experiments made with guinea pig complement. It seemed, therefore, reasonable to investigate in a preliminary way whether or not chicken antibody hæmolyses red cells in the presence of complement from different animal species.

Hæmolytic sera were prepared by inoculating intravenously Rhode Island Red pullets with 5 per cent suspension of duck and rabbit erythrocytes (two series of three injections each, followed by re-injection. after 20 days). The diluent for all reagents was sodium chloride-veronal buffer $p \mathrm{H} 7 \cdot 3-7 \cdot 4$ containing 